\title{
Factors associated with the use of complementary and alternative therapies among patients with hypertension and type 2 diabetes mellitus in Western Jamaica: a cross-sectional study
}

Samuel Owusu', Yai-Ellen Gaye ${ }^{1}$, Skyla Hall ${ }^{1}$, Anna Junkins' ${ }^{1}$, Maira Sohail', Sarah Franklin ${ }^{1}$, Maung Aung ${ }^{2}$ and Pauline E. Jolly ${ }^{1 *}$ (D)

\begin{abstract}
Background: This study examined the prevalence and predictors of complementary and alternative medicine use among clinic patients with hypertension and/or type 2 diabetes mellitus in western Jamaica.

Methods: A cross-sectional study using an investigator-administered questionnaire was conducted from May to August 2017. Data on sociodemographic factors, complementary and alternative medicine use, and knowledge and perceptions of complementary and alternative medicine were collected from the patients. Multivariable logistic regression analysis was used to examine associations between patient characteristics and knowledge and perceptions of complementary and alternative medicine and complementary and alternative medicine use.

Results: A total of 362 patients were invited to participate and 345 (95.3\%) completed the questionnaire; 311 (90.1\%) had hypertension, 130 (37.7\%) had type 2 diabetes mellitus and 96 (27.8\%) had both diseases. Seventy-nine percent of the participants with hypertension and $65 \%$ with type 2 diabetes mellitus reported current use of complementary and alternative medicine. Self-reported knowledge of complementary and alternative medicine (none/poor vs average/good/excellent) was significantly associated with complementary and alternative medicine use for hypertension ( $\mathrm{AOR}=0.33,95 \% \mathrm{Cl}=0.13-0.87$ ) and type 2 diabetes mellitus ( $\mathrm{AOR}=0.06,95 \% \mathrm{Cl}=0.01-0.37$ ). Believing that complementary and alternative medicine is a natural method for treating hypertension was significantly associated with complementary and alternative medicine use among patients with hypertension $(A O R=3.9,95 \% \mathrm{Cl}=1.26-12.00)$, and belief that it is acceptable to use prescription medication and complementary and alternative medicine simultaneously was significantly associated with complementary and alternative medicine use among patients with type 2 diabetes mellitus ( $A O R=7.19, \mathrm{Cl}=1.34-38.52)$.
\end{abstract}

(Continued on next page)

\footnotetext{
* Correspondence: jollyp@uab.edu

'Department of Epidemiology, School of Public Health, University of

Alabama at Birmingham, 1665 University Boulevard, Birmingham, AL 35294-0022, USA

Full list of author information is available at the end of the article
}

(c) The Author(s). 2020 Open Access This article is licensed under a Creative Commons Attribution 4.0 International License, which permits use, sharing, adaptation, distribution and reproduction in any medium or format, as long as you give appropriate credit to the original author(s) and the source, provide a link to the Creative Commons licence, and indicate if changes were made. The images or other third party material in this article are included in the article's Creative Commons licence, unless indicated otherwise in a credit line to the material. If material is not included in the article's Creative Commons licence and your intended use is not permitted by statutory regulation or exceeds the permitted use, you will need to obtain permission directly from the copyright holder. To view a copy of this licence, visit http://creativecommons.org/licenses/by/4.0/ The Creative Commons Public Domain Dedication waiver (http://creativecommons.org/publicdomain/zero/1.0/) applies to the data made available in this article, unless otherwise stated in a credit line to the data. 
(Continued from previous page)

Conclusions: Participants' perceptions of their knowledge and beliefs regarding complementary and alternative medicine strongly influence their use of complementary and alternative medicine. These findings can be used in designing educational interventions to promote the proper use, and mitigate detrimental effects, of complementary and alternative medicine in this population.

Keywords: Complementary and alternative medicine, Hypertension, Type 2 diabetes, Herbal medicine, Jamaica

\section{Background}

Hypertension (HTN) and Type 2 Diabetes Mellitus (T2DM) are major health problems globally. HTN is one of the most common non-communicable diseases, affecting up to $20 \%$ of the world's adult population [1]. It was estimated that in 2017, 424 million people worldwide were suffering from Diabetes Mellitus (DM), with $50 \%$ undiagnosed and believed to be unaware of their illness [2]. The prevalence of DM is projected to rise to 628 million by 2045 [2]. T2DM accounts for $90 \%$ of cases of DM, and chronically affected patients can suffer from retinopathy, nephropathy, neuropathy, HTN, dyslipidemia, myocardial infarction, and stroke [3].

Several types of complementary and alternative medicines (CAM) are used worldwide for the treatment of HTN and T2DM. CAM is defined as "practices, approaches, knowledge, and beliefs that incorporate plant, animal and mineral-based medicines, spiritual therapies, manual techniques, and exercise" [4]. Individuals may choose an alternative or "natural" medical treatment because of beliefs or negative experiences with the mainstream medical community, lack of success with prescribed medicine, influence from friends and family, or negative experiences with healthcare providers (HCPs) [5]. In addition, CAM may be more easily accessible and less expensive than prescription medications [5]. Previous research shows that up to $80 \%$ of people living with T2DM use CAM. CAM use varied from $24 \%$ in the United Kingdom to $80 \%$ in Africa [6]. Most diabetic patients commonly use herbal medicine, nutritional supplements, diet modifications, spiritual healing, and relaxation techniques [4]. Despite the widespread use, a high proportion of patients might not disclose CAM use to their HCPs [7].

HTN has become a growing major public health problem for Caribbean countries in this century, with prevalence rates ranging from $26 \%$ for those over 25 years, and up to $55 \%$ for those over 40 years [8]. Half of the population aged $\geq 60$ years is estimated to be living with HTN in Latin America and the Caribbean. People of black racial origin are at higher risk for developing HTN; therefore, Caribbean countries with predominately black populations, such as Jamaica and Barbados have higher prevalence rates of HTN [9]. In Jamaica, the estimated prevalence rate of HTN for persons aged 15-74 years is $25 \%$ [9]. Females were shown to be three times more likely to develop HTN than males and obese individuals were four times more likely to develop HTN than those with normal weight [10]. Other risk factors for HTN include: increasing age, family history of HTN, nutritional intake, salt intake, chronic stress, physical activity, and T2DM $[9,10]$.

T2DM has become an increasing problem in Latin America and the Caribbean in recent years, with certain Latin American countries having some of the highest prevalence rates globally [11]. In 2017, the total number of diagnosed cases of T2DM among adults $20-79$ years in Jamaica was 209,300 [12]. The rate of T2DM cases increases with age. In 2015, Jamaicans aged 55-79-years had prevalence rates of T2DM ranging between 20 and $30 \%$; those aged $20-34$ years had prevalence rates of only $3-7 \%$ [12]. The cost of DM-related health care for adults in Latin America and Caribbean countries in 2000 was estimated at 65 billion United States Dollars (USD) [13]. Modifications in lifestyle such as exercise, weight loss, proper nutrition, and a low-fat diet are important in the management of T2DM.

"Bush" or herbal medicine use in the Caribbean is well documented. Herbs are widely used in treating conditions ranging from the common cold to chronic conditions such as HTN and T2DM [14-16]. Jamaican history shows that there has been a very high reliance on using medicinal plants as treatments for ailments [17]. A study conducted among black Caribbean patients found that $72.6 \%$ of participants reported regular use of herbal medicine to treat an illness or maintain good health in the past 12 months [15]. Of those who reported herbal medicine use, $77 \%$ reported using herbal medicine to treat respiratory illnesses and 53\% to treat gastrointestinal problems [15]. Smaller percentages of participants reported the use of herbal treatments for HTN (15\%) and T2DM (4\%) [15]. Another study that examined the use of bush medicine in Trinidad and Tobago found that $42 \%$ of participants reported using herbs, and $24 \%$ reported using herbs for T2DM [16]. A study conducted in Jamaica in 2006 on the concomitant use of prescription medicines and herbs for a variety of ailments found that 83.2 and $79.5 \%$ of participants practiced concomitant herb-prescription medicine use for DM and HTN, respectively [18]. 
However, recent scientific literature on the use of CAM in the treatment of HTN and T2DM from the Caribbean, and Jamaica in particular, is sparse. Therefore, we conducted this research to investigate CAM use among patients diagnosed with HTN and T2DM in western Jamaica. We investigated associations between knowledge and perceptions of CAM and CAM use among the patients. The findings from this study can be used in the development of educational interventions that promote the appropriate use, and mitigate detrimental effects, of CAM in treating HTN and T2DM.

\section{Methods}

\section{Study design, setting, and population}

A cross-sectional study was conducted among patients $\geq 18$ years of age attending any of seven chronic disease clinics for HTN and/or T2DM in the four parishes (St. James, Westmoreland, Hanover and Trelawny) under the Western Regional Health Authority (WRHA) of Jamaica. Nurses in these clinics informed eligible patients about the study, and those who expressed willingness to participate were directed to the research staff who provided further information and obtained informed consent from all patients who volunteered to participate.

\section{Inclusion and exclusion criteria}

To be eligible to participate in the study patients had to be adults, $\geq 18$ years of age who had been diagnosed with HTN and/or T2DM and were attending a chronic disease clinic in one of the four parishes under the WRHA. Patients who did not meet these inclusion criteria were excluded. A signed informed consent was obtained from each patient who agreed to participate.

\section{Sample size and sampling method}

Based on previous estimates of concomitant use of herb and prescription medication among hypertensive (79.5\%) and diabetic $(83.2 \%)$ patients in Jamaica, the sample size for the current study was determined to be a minimum of 251 hypertensive and 215 diabetic patients with a 95\% confidence limit and 5\% margin of error [18]. The sample was calculated using the online calculator EpiTools by Ausvet $\odot$ (http://epitools.ausvet.com.au). A convenience sampling method was used to recruit patients at the clinics during the study period. Patients attending the chronic disease clinics who met the inclusion criteria were eligible to participate and were included in the study if they agreed and signed the informed consent.

\section{Questionnaire development and data collection}

An investigator-administered questionnaire was used to collect data on sociodemographic factors (age, education, employment status, income, and residence), CAM use, knowledge and perception of CAM, and concomitant use of prescription medicine and CAM. Questions on education level, income, and occupation were important since previous studies found that income and education level can influence knowledge and use of CAM. Questions on knowledge of CAM, perception of CAM, and concomitant use of CAM with prescription medicines were adapted from questions used in published studies on CAM that were conducted in Jamaica, as well as other Caribbean and non-Caribbean countries. Questions were included to allow participants to list the types of CAM they were using for HTN or T2DM. The questionnaire was reviewed by Jamaican HCPs and revised. It was then pilot tested among 10 clinic patients in Jamaica similar to the ones recruited for the study and revised before use.

\section{Data analysis}

Bivariate analyses using chi-square tests were conducted to determine statistically significant differences between sociodemographic characteristics, prescription medication use, self-reported knowledge of CAM, and perception of CAM with CAM use among hypertensive and diabetic patients separately. Sociodemographic variables included in the analyses were age, sex, parish, education, religious affiliation, marital status, occupation, monthly income, number of adults living in a household (NALH), number of children living in a household (NCLH), and time since HTN or T2DM diagnosis.

Logistic regression analysis estimated odds ratios (OR), adjusted odds ratios (AOR), and corresponding 95\% confidence intervals predicting CAM use for treatment of HTN and T2DM separately. Multivariable models included variables that were statistically significant in bivariate analyses. Statistical Analysis System (SAS, Cary, North Carolina, USA) version 9.4 was used for the analyses.

\section{Ethics approval}

The study was reviewed and approved by the Institutional Review Board at the University of Alabama at Birmingham and the Western Regional Health Authority in Jamaica.

\section{Results}

Sociodemographic characteristics associated with CAM use for HTN and T2DM (Table 1)

Among the 345 patients included in the study, 311 had HTN, 130 had T2DM, and 96 had both diseases; about half $(52 \%)$ were $\geq 60$ years of age and $76.5 \%$ were female (Table 1). Current use of CAM was reported by $79.4 \%$ of participants with HTN and by $65.4 \%$ with T2DM (Table 1). Sex and parental status were marginally associated with CAM use for HTN (Table 1). A greater 
Table 1 Sociodemographic characteristics of patients with hypertension (HTN) and Type 2 diabetes mellitus (T2DM) by CAM use

\begin{tabular}{|c|c|c|c|c|c|c|c|}
\hline \multirow[t]{2}{*}{ Variables } & \multirow[t]{2}{*}{$\begin{array}{l}\text { All } \\
(n=345)\end{array}$} & \multicolumn{3}{|l|}{$\begin{array}{l}\text { HTN } \\
(n=311)\end{array}$} & \multicolumn{3}{|l|}{$\begin{array}{l}\text { T2DM } \\
(n=130)\end{array}$} \\
\hline & & $\begin{array}{l}\text { Used CAM } \\
247(79.4)\end{array}$ & $\begin{array}{l}\text { Did not use CAM } \\
64(20.6)\end{array}$ & $p$-valuet & $\begin{array}{l}\text { Used CAM } \\
85(65.4)\end{array}$ & $\begin{array}{l}\text { Did not use CAM } \\
45(34.6)\end{array}$ & $p$-valuet \\
\hline Age (years) & & & & 0.116 & & & 0.052 \\
\hline $18-49$ & $85(24.9)$ & $64(26.1)$ & $9(14.3)$ & & $17(20.2)$ & $7(15.6)$ & \\
\hline $50-59$ & $80(23.5)$ & $55(22.5)$ & $14(22.2)$ & & $25(29.8)$ & $6(13.3)$ & \\
\hline$\geq 60$ & $176(51.6)$ & $126(51.4)$ & $40(63.5)$ & & $42(50.0)$ & $32(71.1)$ & \\
\hline Sex & & & & 0.063 & & & 0.526 \\
\hline Male & $81(23.5)$ & $50(20.3)$ & $20(31.3)$ & & $22(25.9)$ & $14(31.1)$ & \\
\hline Female & $263(76.5)$ & $196(79.7)$ & $44(68.8)$ & & $63(74.1)$ & $31(68.9)$ & \\
\hline Parish & & & & 0.678 & & & 0.626 \\
\hline Hanover & $21(6.1)$ & $14(5.7)$ & $5(7.8)$ & & $3(3.5)$ & $1(2.2)$ & \\
\hline St. James & $188(54.5)$ & $140(56.7)$ & $32(50.0)$ & & $39(45.9)$ & $25(55.6)$ & \\
\hline Westmoreland & 109 (31.6) & $74(30.0)$ & $23(35.9)$ & & $35(41.2)$ & $17(37.8)$ & \\
\hline Trelawny & $27(7.8)$ & $19(7.7)$ & $4(6.3)$ & & $8(9.4)$ & $2(4.4)$ & \\
\hline Marital status & & & & 0.895 & & & 0.199 \\
\hline Never married & $152(44.0)$ & $105(42.5)$ & $26(40.6)$ & & $43(50.6)$ & $18(40.0)$ & \\
\hline Married/common law & $132(38.3)$ & $98(39.7)$ & $25(39.1)$ & & $28(32.9)$ & $22(48.9)$ & \\
\hline Divorced/Widowed & $61(17.7)$ & $44(17.8)$ & $13(20.3)$ & & $14(16.5)$ & $5(11.1)$ & \\
\hline Education & & & & 0.763 & & & 0.842 \\
\hline Primary or less & $165(48.0)$ & $121(49.0)$ & $30(46.9)$ & & $39(45.9)$ & $21(47.7)$ & \\
\hline $\begin{array}{l}\text { Some or completed Secondary/ } \\
\text { College/University }\end{array}$ & $179(52.0)$ & $126(51.0)$ & $34(53.1)$ & & $46(54.1)$ & $23(52.3)$ & \\
\hline Religious affiliation & & & & 0.663 & & & 0.427 \\
\hline Catholic/Protestant Christian & $235(68.1)$ & $167(67.6)$ & $41(64.1)$ & & $64(75.3)$ & $29(64.4)$ & \\
\hline Adventist & $72(20.9)$ & $55(22.3)$ & $14(21.9)$ & & $13(15.3)$ & $10(22.2)$ & \\
\hline Muslim/Jehovah Witness/ & $38(11.0)$ & $25(10.1)$ & $9(14.1)$ & & $8(9.4)$ & $6(13.3)$ & \\
\hline Occupation & & & & 0.458 & & & 0.762 \\
\hline Unskilled & $269(78.0)$ & $190(76.9)$ & $52(81.3)$ & & $70(82.4)$ & $38(84.4)$ & \\
\hline Professional/Skilled/ Clerical/Other & $76(22.0)$ & $57(23.1)$ & $12(18.8)$ & & $15(17.7)$ & $7(15.6)$ & \\
\hline Income & & & & 0.454 & & & 0.347 \\
\hline No Income & $190(55.1)$ & $130(52.6)$ & $39(60.9)$ & & $53(62.4)$ & $33(73.3)$ & \\
\hline$<J \$ 24,800$ & $94(27.3)$ & $71(28.7)$ & $14(21.9)$ & & $20(23.5)$ & $9(20.0)$ & \\
\hline$\geq J \$ 24,801$ & $61(17.7)$ & $46(18.6)$ & $11(17.2)$ & & $12(14.1)$ & $3(6.7)$ & \\
\hline Have children & $319(92.7)$ & $226(91.9)$ & $63(98.4)$ & 0.063 & $75(88.2)$ & $42(93.3)$ & 0.357 \\
\hline Number of adults in household & & & & & & & 0.068 \\
\hline 1 & $79(23.1)$ & $51(20.8)$ & $16(25.4)$ & 0.561 & $27(31.8)$ & $15(34.1)$ & \\
\hline $2-3$ & $172(50.3)$ & $125(51.0)$ & $33(52.4)$ & & $36(42.4)$ & $25(56.8)$ & \\
\hline$\geq 4$ & $91(26.6)$ & $69(28.2)$ & $14(22.2)$ & & $22(25.9)$ & $4(9.1)$ & \\
\hline Number of children in household & & & & 0.318 & & & 0.801 \\
\hline$\leq 1$ & $263(77.1)$ & $183(75.3)$ & $52(81.3)$ & & $72(84.7)$ & $38(86.4)$ & \\
\hline$\geq 2$ & $78(22.9)$ & $60(24.7)$ & $12(18.8)$ & & $13(15.3)$ & $6(13.6)$ & \\
\hline Time of diagnosis & & & & 0.358 & & & 0.259 \\
\hline$<10$ years ago & $150(48.9)$ & $122(50.2)$ & $28(43.8)$ & & $38(45.2)$ & $24(55.8)$ & \\
\hline$\geq 10$ years ago & $157(51.1)$ & $121(49.8)$ & $36(56.2)$ & & $46(54.8)$ & $19(44.2)$ & \\
\hline
\end{tabular}

$+P$-value based on chi-square

$-\$ 24,800=$ Jamaican minimum wage at the time of the study, CAM Complementary and alternative medicine 
proportion of CAM users compared to non-CAM users were female ( $80 \%$ vs. $69 \%)$. Among patients with T2DM, age and the number of adults in the household were marginally associated with use of CAM; $71 \%$ of those who did not use CAM were $\geq 60$ years of age.

\section{Most common alternative therapies used for treatment of HTN and T2DM}

The most common CAM method used (answers are not mutually exclusive) by participants with HTN was herbal medicine (72.1\%); this was followed by diet modification (46.6\%), exercise (40.1\%), nutritional supplements (15.4\%), relaxation techniques $(9.3 \%)$, spiritual healing (6.5\%) and manual techniques (0.8\%). For T2DM, the most common CAM method reported was herbal medicine (65.9\%); this was followed by diet modification $(52.9 \%)$, exercise $(41.2 \%)$, relaxation techniques and spiritual healing (10.6\% each), and nutritional supplements
(9.4\%). The most commonly reported herbal medicines used for HTN were, Garlic (Allium sativum), Soursop (Annona muricate), Cerasee (Momordica charantia), Guinea Hen Weed (Petiveria alliacea), and Coconut water (Cocos nucifera) with lime (Citrus aurantiifolia). For T2DM, the most common herbal medicines reported were Cerasee (Momordica charantia), Bird Pepper (Capsicum annuum), Coconut water (Cocos nucifera), Pound-cake Bush (Parthenium hysterophorus), and King of the Forest (Cassia alata).

Prescription medication use associated with CAM use for HTN and T2DM (Table 2)

The majority of patients in the study (94\%) were prescribed medication for HTN (91.3\%) or DM (93.8\%), and approximately $58 \%$ received their prescription medication from the hospital or health center $(\sim 58 \%)$; approximately $76-77 \%$ reported filling their HTN prescription

Table 2 Prescription medication association with CAM use among patients with hypertension (HTN) and type 2 diabetes mellitus (T2DM)

\begin{tabular}{|c|c|c|c|c|c|c|}
\hline \multirow[t]{2}{*}{ Variables } & \multicolumn{3}{|l|}{$\begin{array}{l}\text { Hypertension } \\
(n=311)\end{array}$} & \multicolumn{3}{|c|}{$\begin{array}{l}\text { Type } 2 \text { Diabetes Mellitus } \\
(n=130)\end{array}$} \\
\hline & Used CAM 247 (79.4) & $\begin{array}{l}\text { Did not use } \\
\text { CAM } 64(20.6)\end{array}$ & $p$-valuet & Used CAM 85 (65.3) & Did not use CAM 45 (34.6) & $p$-value \\
\hline Prescribed medicine for HTN/DM & & & 0.080 & & & 0.860 \\
\hline Yes & $221(89.8)$ & $61(96.8)$ & & $80(94.1)$ & $42(93.3)$ & \\
\hline No & $25(10.2)$ & $2(3.2)$ & & $5(5.9)$ & $3(6.7)$ & \\
\hline Provider of prescription medicine & & & 0.936 & & & 0.170 \\
\hline Hospital/Health center & $129(58.6)$ & $36(58.1)$ & & $44(58.7)$ & $30(71.4)$ & \\
\hline Pharmacy & $91(41.4)$ & $26(41.9)$ & & $31(41.3)$ & $12(28.6)$ & \\
\hline Pay for medication & & & 0.220 & & & 0.014 \\
\hline No & $71(32.0)$ & $25(40.3)$ & & $18(23.7)$ & $18(46.2)$ & \\
\hline Yes & $151(68.0)$ & $37(59.7)$ & & $58(76.3)$ & $21(53.9)$ & \\
\hline Refill medicine on-time & & & 0.787 & & & 0.163 \\
\hline Yes & $172(75.8)$ & $48(77.4)$ & & $57(73.1)$ & 33 (84.6) & \\
\hline No/Sometimes & $55(24.2)$ & $14(22.6)$ & & $21(26.9)$ & $6(15.4)$ & \\
\hline Take medicine as prescribed & & & 0.299 & & & 0.153 \\
\hline Always & $110(48.3)$ & $34(55.7)$ & & $41(51.3)$ & $26(65.0)$ & \\
\hline Not Always & $118(51.8)$ & $27(44.3)$ & & $39(48.8)$ & $14(35.0)$ & \\
\hline Medicine controlling disease & & & 0.051 & & & 0.937 \\
\hline Yes & $172(77.5)$ & $55(88.7)$ & & $67(85.9)$ & $35(85.4)$ & \\
\hline No/Sometimes & $50(22.5)$ & $7(11.3)$ & & $11(14.1)$ & $6(14.6)$ & \\
\hline Discontinues medicine when BP n & hormal & & 0.099 & & & \\
\hline Yes/Sometimes & $74(33.2)$ & $13(22.0)$ & & & & \\
\hline No & $149(66.8)$ & $46(78.0)$ & & & & \\
\hline $\begin{array}{l}\text { Experience side effects from } \\
\text { medicine }\end{array}$ & & & 0.781 & & & 0.013 \\
\hline Yes & $73(33.0)$ & $19(31.2)$ & & $32(41.0)$ & $7(18.0)$ & \\
\hline No & $148(67.0)$ & $42(68.9)$ & & $46(59.0)$ & $32(82.1)$ & \\
\hline
\end{tabular}

CAM Complementary and alternative medicine 
on time (Table 2). Among participants with HTN, those who did not use CAM were more likely to report that their prescription medication was controlling their HTN and were less likely to discontinue medication when their blood pressure was normal compared to CAM users. Among participants with T2DM, those who used CAM were more likely to pay for their medication ( $76.3 \%$ vs. $53.9 \% ; p=0.014)$ and much more likely to report that they experience side effects from their prescription medication versus those who did not use CAM $(41.0 \%$ vs. $18.0 \% ; p=0.013)$.

\section{Self-reported knowledge, perceptions, and use of CAM} for HTN and T2DM (Table 3)

Most participants reported receiving information about CAM from friends, family members, or the media

Table 3 Self-reported knowledge and perceptions of CAM and CAM use for hypertension (HTN) and type 2 diabetes mellitus (T2DM)

\begin{tabular}{|c|c|c|c|c|c|c|}
\hline & \multicolumn{3}{|l|}{$\begin{array}{l}\text { HTN } \\
(n=311)\end{array}$} & \multicolumn{3}{|l|}{$\begin{array}{l}\text { T2DM } \\
(n=130)\end{array}$} \\
\hline & $\begin{array}{l}\text { Used CAM } \\
247(79.4)\end{array}$ & $\begin{array}{l}\text { Did not use } \\
\text { CAM } 64(20.6)\end{array}$ & $p$-valuet & $\begin{array}{l}\text { Used CAM } \\
85(65.3)\end{array}$ & $\begin{array}{l}\text { Did not use } \\
\text { CAM } 45(34.6)\end{array}$ & $p$-value \\
\hline Received information about CAM & $51(79.7)$ & $14(63.6)$ & 0.131 & $66(86.8)$ & $25(27.5)$ & 0.002 \\
\hline Source of information on CAM & & & 0.076 & & & 0.834 \\
\hline HCP/clinic staff & $38(21.0)$ & $3(8.3)$ & & $10(21.3)$ & $4(19.1)$ & \\
\hline Friend/family member/Media & $143(79.0)$ & $33(91.7)$ & & $37(78.7)$ & $17(81.0)$ & \\
\hline Heard positive or negative information about CAM ${ }^{a}$ & & & 0.271 & & & 0.252 \\
\hline Yes & $210(90.9)$ & $42(85.7)$ & & $74(93.7)$ & $35(87.5)$ & \\
\hline No & $21(9.1)$ & $7(14.3)$ & & $5(6.3)$ & $5(12.5)$ & \\
\hline Self-reported knowledge of CAM & & & $<0.0001$ & & & $<0.001$ \\
\hline None/Some & $119(49.2)$ & $48(81.4)$ & & $37(45.1)$ & $35(83.3)$ & \\
\hline Average/Good/Excellent & $123(50.8)$ & $11(18.6)$ & & $45(54.9)$ & $7(16.7)$ & \\
\hline Discussed CAM with healthcare provider & & & 0.004 & & & 0.008 \\
\hline Yes & $62(25.9)$ & $5(8.3)$ & & $21(28.4)$ & $3(7.3)$ & \\
\hline No & $177(74.1)$ & $55(91.7)$ & & $53(71.6)$ & $38(92.7)$ & \\
\hline Always discuss any CAM for your condition with your HCP & & & 0.211 & & & 0.356 \\
\hline Yes & $170(70.5)$ & $37(59.7)$ & & $55(67.9)$ & $25(59.5)$ & \\
\hline No & $70(29.1)$ & $25(40.3)$ & & $26(32.1)$ & $17(40.5)$ & \\
\hline Perceives that a normal blood pressure reading means that. & & & 0.941 & & & \\
\hline Cured of disease & $11(5.0)$ & $3(5.3)$ & & & & \\
\hline Blood pressure is normal at the time, but disease still present & $208(95.0)$ & $54(94.7)$ & & & & \\
\hline Believes CAM is a natural method for treating the disease & $165(68.5)$ & $30(48.4)$ & 0.010 & $60(73.2)$ & $27(62.8)$ & 0.231 \\
\hline Perceives that it is acceptable to use prescription medication and & CAM simultar & heously & 0.058 & & & 0.083 \\
\hline Yes & $72(29.8)$ & $11(16.7)$ & & $27(33.3)$ & $8(18.6)$ & \\
\hline No & $170(70.3)$ & $51(83.3)$ & & $54(66.7)$ & $35(81.4)$ & \\
\hline $\begin{array}{l}\text { Perceives that it is acceptable to stop taking medicine without cc } \\
\mathrm{HCP} \text { if experiencing unpleasant side effects }\end{array}$ & nsulting & & 0.018 & & & 0.031 \\
\hline Yes & $80(33.2)$ & $11(16.7)$ & & $30(37.5)$ & $8(18.6)$ & \\
\hline No & $161(66.8)$ & $51(83.3)$ & & $50(62.5)$ & $35(81.4)$ & \\
\hline Perceives that CAM should always be used instead of prescription & medication & & 0.003 & & & 0.462 \\
\hline Yes & $101(41.6)$ & $13(21.0)$ & & $27(32.9)$ & $17(39.5)$ & \\
\hline No & $142(58.4)$ & $49(79.0)$ & & $55(67.1)$ & $26(60.5)$ & \\
\hline Perceives that CAM is more effective at treating disease than pre & cription & & 0.105 & & & 0.062 \\
\hline Yes & $89(36.8)$ & $16(25.8)$ & & $30(36.6)$ & $14(32.6)$ & \\
\hline No & $153(63.2)$ & $46(74.2)$ & & $44(53.7)$ & $18(41.9)$ & \\
\hline
\end{tabular}

ancluding that CAM is as good as or better than prescription medication, is effective, accessible, does not have side effects, and is inexpensive, is worse than prescription medication, is ineffective, has side effects, and is expensive; CAM Complementary and alternative medicine 
(Table 3). Several factors related to knowledge and perceptions of CAM were found to be associated with CAM use by both participants with HTN and T2DM. These include: 1) self-reported knowledge of CAM, 2) previously discussing CAM with a $\mathrm{HCP}, 3$ ) acceptability of simultaneous use of CAM and prescription medicine, and 4) acceptability of discontinuing use of prescription medication without consulting a HCP if side effects are experienced (Table 3). Additionally, the source of CAM information, belief that CAM is a natural method for treating HTN, and a perception that CAM should always/sometimes be used instead of prescription medicine were associated with CAM use among patients with HTN. For patients with T2DM, having received information on CAM and a perception that CAM is more effective than prescription medication at treating $\mathrm{DM}$ were associated with CAM use (Table 3).

\section{Predicted odds of using CAM for HTN (Table 4)}

Among participants with HTN, self-reported knowledge of CAM and believing that CAM is a natural method for treating HTN were significantly associated with use of CAM, even after adjustment for covariates (Table 4). Participants who reported none/some knowledge of CAM were $67 \%$ less likely to use CAM compared to those who reported average/good/excellent knowledge of CAM (AOR $=0.33, \mathrm{CI}=0.13-0.87$ ). Those who believed that CAM is a natural method for treating HTN were 3.9 times more likely to use $\mathrm{CAM}(\mathrm{AOR}=3.9, \mathrm{CI}=$ $1.26-12.00)$.

\section{Predicted odds of using CAM for T2DM (Table 5)}

Among participants with T2DM, self-reported knowledge of CAM and acceptability of simultaneous use of prescription medicine and CAM were associated with CAM use (Table 5). T2DM patients who reported none/ some knowledge of CAM were $94 \%$ less likely to use CAM compared to those who reported average/good/excellent knowledge of CAM (AOR $=0.06, \mathrm{CI}=0.01-0.37$ ). Those who perceived that it is acceptable to use prescription medication and CAM simultaneously were 7.19 times more likely to use CAM compared to those who $\operatorname{did} \operatorname{not}(\mathrm{AOR}=7.9, \mathrm{CI}=1.34-38.52)$.

\section{Discussion}

This study describes the prevalence and factors associated with CAM use by patients for treatment of HTN and T2DM in western Jamaica. More than one-quarter (28\%) of the patients had both HTN and T2DM. HTN and T2DM frequently coexist, leading to increase in the risk of life-threatening complications. The high proportion of females $(76.5 \%)$ in the study can be explained by the fact that females are a high-risk group for developing HTN in Jamaica. Previous research in Jamaica suggests that females are three times more likely to develop HTN compared to males [10]. Thus, our enrollment of $76.5 \%$ females exactly matches this reported prevalence.

Our finding of a high prevalence of CAM use among patients with both HTN and T2DM is consistent with that of a study that reported herbal medicine to treat ailments and maintain health by $72.6 \%$ of Jamaicans [15]. Our results are also consistent with the findings of some studies conducted globally that show CAM usage of 17$80 \%$, with the highest rates in Africa [6]. The reason for the high use of herbal medicine in Jamaica could be attributed to the fact that herbs are a part of the daily lives of many Jamaicans since they are often consumed as tea [19]. However, the increased interest, belief, and use of CAM in Jamaica in the mid-late 1990s, and Jamaica's poor economic situation, may have helped to facilitate the increased use of herbs [20,21]. The medications associated with the treatment for HTN and T2DM are lengthy and costly. The study by Delgoda et al., found that those of high socioeconomic status and those with health insurance had much lower use of combined herb and prescription medication, further strengthening the idea that the boom in herbal use was in part due to financial reasons [18].

In this study, over $60 \%$ of participants with T2DM and $70 \%$ with HTN used CAM simultaneously with prescription medicine. A previous study found that almost $80 \%$ of patients with HTN and $83 \%$ with T2DM practiced concomitant use of CAM and prescription drugs; $94 \%$ of respondents believed that there was no harm in taking CAM and prescription medication concomitantly [18]. Over two-thirds of participants in our study said that it was unacceptable to use prescription medicine and CAM simultaneously. However, patients with T2DM who believed that simultaneous use of CAM and prescription medicine was acceptable were seven times more likely to use CAM, and patients with HTN who believed that CAM is a natural method for treating disease were almost 4 times more likely to use CAM. These findings clearly show that patients' beliefs regarding CAM strongly determine their use CAM and point to the need for appropriate counseling on the use of CAM, especially along with prescription medication, in order to mitigate possible harmful effects of simultaneous use of CAM and prescription medicine. For example, garlic (Allium sativum) which is commonly used in Jamaica to treat HTN and T2DM, has been shown to have antihypertensive, hypoglycemic, and lipid-lowering properties and therefore could cause adverse health effects if taken simultaneously with prescribed medication for HTN and T2DM [22, 23].

In the current study, self-reported knowledge of CAM was significantly associated with CAM use among patients with HTN and T2DM. In both groups, patients 
Table 4 Odds ratios (OR) and 95\% confidence intervals (CI) for the associations of knowledge and perception of CAM and CAM use for the treatment of hypertension $(\mathrm{HTN})^{\mathrm{a}}$

\begin{tabular}{|c|c|c|}
\hline & $\begin{array}{l}\text { Crude } \\
\text { OR }(95 \% \mathrm{Cl})\end{array}$ & $\begin{array}{l}\text { Adjusted }^{\mathbf{b}} \\
\text { OR }(95 \% \mathrm{Cl})\end{array}$ \\
\hline \multicolumn{3}{|l|}{ Sex } \\
\hline Male & $0.56(0.30-1.04)$ & $0.51(0.16-1.57)$ \\
\hline Female & Ref & Ref \\
\hline \multicolumn{3}{|l|}{ Children } \\
\hline Yes & $0.18(0.02-1.36)$ & QCS $^{\mathrm{C}}$ \\
\hline No & Ref & Ref \\
\hline \multicolumn{3}{|l|}{ Prescribed medicine } \\
\hline Yes & $0.29(0.07-1.26)$ & QCS $^{\mathrm{C}}$ \\
\hline No & Ref & Ref \\
\hline \multicolumn{3}{|l|}{ Medicine controlling disease } \\
\hline Yes & $0.44(0.19-1.02)$ & $0.61(0.19-1.95)$ \\
\hline No & Ref & Ref \\
\hline \multicolumn{3}{|c|}{ Discontinues medicine when BP normal } \\
\hline Yes & $1.76(0.89-3.45)$ & $1.13(0.40-3.15)$ \\
\hline No & Ref & Ref \\
\hline \multicolumn{3}{|c|}{ Received information about CAM from ... } \\
\hline $\mathrm{HCP} /$ clinic staff & $2.92(0.85-10.05)$ & $1.81(0.34-9.61)$ \\
\hline Friend/family member/Media & Ref & Ref \\
\hline \multicolumn{3}{|l|}{ Self-reported of knowledge of CAM } \\
\hline None/Some & $0.22(0.11-0.45)$ & $0.33(0.13-0.87)$ \\
\hline Average/Good/Excellent & Ref & Ref \\
\hline \multicolumn{3}{|l|}{ Discussed CAM with HCP } \\
\hline Yes & $3.85(1.48-10.06)$ & $2.85(0.68-12.00)$ \\
\hline No & Ref & Ref \\
\hline \multicolumn{3}{|c|}{ Believes CAM is a natural method for treating disease } \\
\hline Yes & $2.35(1.33-4.14)$ & $3.90(1.26-12.00)$ \\
\hline No & Ref & Ref \\
\hline \multicolumn{3}{|c|}{ Perceives that it is acceptable to use prescription medication and CAM simultaneously } \\
\hline Yes & $1.96(0.97-3.98)$ & $1.60(0.55-4.70)$ \\
\hline No & Ref & Ref \\
\hline
\end{tabular}

Perceives that it is acceptable to stop taking prescription medication without consulting HCP if experiencing unpleasant side effects
Yes
$2.30(1.14-4.66)$
$1.10(0.39-3.09)$
No
Ref
Ref

Perceives that CAM should always be used instead of prescription medication

Yes

$2.68(1.38-5.20)$

Ref
$1.21(0.55-2.68)$

Ref

${ }^{a}$ Estimated using logistic regression

b Adjusted model includes significant variables in bivariate analyses: sex, parental status, prescription hypertensive medicine, medicine controlling hypertension, stop taking medicine if $\mathrm{BP}$ normal, perceives that it is acceptable to discontinue prescription medicine without consulting $\mathrm{HCP}$, source from which have received information about CAM, previously discussing CAM with HCP, self-reported knowledge of CAM, perceives that CAM is a natural treatment method, perceives that it is acceptable to use prescription medication and CAM simultaneously to treat hypertension, and perceives that CAM should be used instead of prescription medication all or some of the time

'Quasi-complete separation (QCS), CAM Complementary and alternative medicine 
Table 5 Odds ratios (OR) and 95\% confidence intervals (CI) for the associations of knowledge and perception of CAM and CAM use for the treatment of type 2 diabetes mellitus (T2DM) ${ }^{a}$

\begin{tabular}{|c|c|c|}
\hline & $\begin{array}{l}\text { Crude } \\
\text { OR }(95 \% \mathrm{Cl})\end{array}$ & $\begin{array}{l}\text { Adjusted }^{\mathbf{b}} \\
\text { OR (95\% Cl) }\end{array}$ \\
\hline \multicolumn{3}{|l|}{ Age } \\
\hline $18-49$ & $1.77(0.66-4.76)$ & $3.51(0.66-18.81)$ \\
\hline $50-59$ & $2.60(1.00-6.74)$ & $3.97(0.87-18.05)$ \\
\hline$\geq 60$ & Ref & Ref \\
\hline \multicolumn{3}{|c|}{ Number of adults in household } \\
\hline 0 to 1 & $0.33(0.10-1.13)$ & $2.92(0.45-19.17)$ \\
\hline 2 to 3 & $0.27(0.08-0.86)$ & $0.75(0.13-4.55)$ \\
\hline$\geq 4$ & Ref & Ref \\
\hline \multicolumn{3}{|l|}{ Medication cost } \\
\hline No cost/free & $0.36(0.16-0.82)$ & $0.34(0.09-1.22)$ \\
\hline Have to pay & Ref & Ref \\
\hline \multicolumn{3}{|c|}{ Side effects from medicine } \\
\hline Yes & $3.21(1.27-8.14)$ & $1.65(0.43-6.39)$ \\
\hline No & Ref & Ref \\
\hline
\end{tabular}

Received information about CAM

$\begin{array}{lll}\text { Yes } & \mathbf{3 . 9 6} \mathbf{( 1 . 5 7 - 9 . 9 7 )} & 1.61(0.37-7.03) \\ \text { No } & \text { Ref } & \text { Ref }\end{array}$

Self-reported of knowledge of CAM

\begin{tabular}{|c|c|c|}
\hline None/Some & $0.16(0.07-0.41)$ & $0.06(0.01-0.37)$ \\
\hline Average/Good/Excellent & Ref & Ref \\
\hline \multicolumn{3}{|l|}{ iscussed CAM with HCP } \\
\hline Yes & $4.93(1.37-17.70)$ & $4.71(0.75-29.46)$ \\
\hline No & Ref & Ref \\
\hline
\end{tabular}

Perceives that it is acceptable to use prescription medication and CAM simultaneously

$\begin{array}{lll}\text { Yes } & 2.15(0.88-5.26) & \mathbf{7 . 1 9}(\mathbf{1 . 3 4 - 3 8 . 5 2 )} \\ \text { No } & \text { Ref } & \text { Ref }\end{array}$

Perceives that it is acceptable to stop taking medicine without consulting HCP if experiencing unpleasant side effects
Yes

No
$2.71(1.12-6.60)$

Ref
$0.89(0.20-3.91)$

Ref
Perceives that CAM is more effective at treating disease than prescription medication

$\begin{array}{lll}\text { Yes } & 1.17(0.54-2.56) & 0.99(0.40-2.45) \\ \text { No } & \text { Ref } & \text { Ref }\end{array}$

${ }^{a}$ Estimated using logistic regression

b Adjusted model includes significant variables in bivariate analyses: age, number of adults in household, cost of medication, side effects from medicine, perceives that it is acceptable to discontinue prescription medicine without consulting $\mathrm{HCP}$, previously receiving information about CAM, previously discussing CAM with their HCP, self-reported knowledge of CAM, perceiving that it is acceptable to use prescription medication and CAM simultaneously, and perceives that CAM is more effective at treating disease than prescription; CAM Complementary and alternative medicine who reported that they had no/poor knowledge of CAM were significantly less likely to use CAM than those who reported average/good/excellent knowledge of CAM. Thus, use of CAM by patients seems to be driven by confidence regarding knowledge of CAM. Future studies should assess self-reported knowledge compared with tested knowledge of CAM among participants. This would allow identification of misconceptions regarding CAM and for educational interventions that provide accurate information on CAM to be developed and conducted. In addition to educational interventions on CAM, increasing resources within communities for easy access to routine blood pressure checks and blood glucose readings will help patients to monitor their blood pressure and blood glucose levels frequently. This could help them to understand their illness and document the effects of prescription medicine in controlling their HTN and/or T2DM.

The gap in patient-HCP dialogue regarding CAM use is of particular concern. Only about $20 \%$ of our participants reported that they discussed CAM use with their HCPs. Other studies report that only $18-19 \%$ of medical practitioners are aware of herbal use by their patients $[8$, 24]. This gap in communication between patients and HCPs may be attributed to the fact that many patients expect negative reactions from HCPs about their use of CAM and prefer not to disclose such information [15]. On the other hand, this lack of communication could occur because HCPs do not ask patients about their CAM use [2]. The Jamaican study by Delgoda et al., reported that only $11.3 \%$ of participants who used herbs were asked about CAM use by their doctors. Our results indicate that among the participants who used CAM, only $19-20 \%$ reported that they had received information about CAM from their HCP.

In accordance with the World Health Organization (WHO) 2008 Beijing Declaration, which promotes the safe and effective use of herbal remedies, there is a need for more publicly available information regarding the safe use of herbal remedies [24]. In order to promote appropriate knowledge of CAM in Jamaica, there is need for collaboration between the Ministry of Health and health educational institutions (schools of nursing, medicine, nutrition, pharmacy and public health) on training in CAM and communication with patients.

\section{Limitations}

There are limitations that should be considered in interpreting the results of this study. First, the sample of patients with T2DM is small and may affect generalizability of the results from the current study to the population of diabetic patients in the Western region or other regions of Jamaica. Secondly, the study sample represents only patients who attended the chronic disease clinics in the WRHA that were included in the study; therefore, the 
results may not be generalizable to patients attending other clinics or parishes that were not sampled. Additionally, the data were self-reported and as a result might be subject to social desirability bias.

\section{Conclusions}

Regardless of the limitations, this study identified factors such as self-reported knowledge of CAM, belief that CAM is a natural method for treating HTN, and belief that it is acceptable to use CAM and prescription medication simultaneously to treat T2DM, to be significantly associated with CAM use. These findings strongly suggest the need for educational interventions for both patients and HCPs to address the gaps in knowledge and communication of CAM and to ensure proper use of CAM in treating HTN and T2DM. This is important for the appropriate management of these major debilitating diseases in the Jamaican society.

\section{Abbreviations \\ HTN: Hypertension; T2DM: Type 2 Diabetes Mellitus; DM: Diabetes Mellitus; CAM: Complementary and alternative medicine; HCP: Healthcare provider; USD: United States Dollar.; WRHA: Western Regional Health Authority; NALH: Number of adults living in household; NCLH: Number of children living in household; OR: Odds ratio; AOR: Adjusted odds ratio; 95\% Cl: 95\% Confidence interval}

\section{Acknowledgements}

We thank the nurses in the clinics who facilitated the study and the patients who participated.

\section{Authors' contributions \\ The study was conceived and designed by PEJ and MA. SF and PJ developed the protocol and questionnaire. SO, YEG, SH, MA and PEJ revised the protocol and questionnaire. SO, YEG, SH collected and entered the data. AJ and MS analyzed the data, prepared the tables and wrote the statistical analysis method. AJ, PJ, MA, SO and YEG interpreted the data. SF, SO, YEG drafted the manuscript and all authors reviewed, revised, and approved the manuscript.}

\section{Funding}

This study was supported by the Minority Health International Research Training grant no. T37-MD001448 from the National Institute on Minority Health and Health Disparities, National Institutes of Health, Bethesda, Maryland, USA, and the Western Regional Health Authority, Ministry of Health, Jamaica.

\section{Availability of data and materials}

The datasets generated and/or analyzed during the current study are not publicly available due to the fact that further analysis is still being conducted on the data but are available from the corresponding author on reasonable request.

\section{Ethics approval and consent to participate}

Participation in the study was voluntary and a signed informed consent was obtained from each participant. The study was approved by the Institutional Review Board at the University of Alabama at Birmingham, and the Western Regional Health Authority; protocol approval \#IRB-170310006.

\section{Consent for publication}

All participants consented for their data to be used in publication.

\section{Competing interests}

All authors declare that they have no competing interests.

\section{Author details}

'Department of Epidemiology, School of Public Health, University of Alabama at Birmingham, 1665 University Boulevard, Birmingham, AL 35294-0022, USA. Epidemiology Unit, Western Regional Health Authority, Ministry of Health, Montego BaySt. JamesJamaica.

Received: 14 January 2020 Accepted: 8 October 2020

Published online: 17 October 2020

\section{References}

1. Osamor PE, Owumi BE. Complementary and alternative medicine in the management of hypertension in an urban Nigerian community. BMC Complement Altern Med. 2010;10:36. Published 2010 Jul 19. https://doi.org/ 10.1186/1472-6882-10-36.

2. International Diabetes Federation. IDF Diabetes Atlas 8th Edition. 2017. https://www.idf.org/e-library/epidemiology-research/diabetes-atlas. Accessed June 1, 2019.

3. Dey L, Attele AS, Yuan CS. Alternative therapies for type 2 diabetes. Altern Med Rev. 2002 Feb;7(1):45-58.

4. Matheka DM, Alkizim FO. Complementary and alternative medicine for type 2 diabetes mellitus: role of medicinal herbs. J Diabetes Endocrinol. 2012;3(4): 44-56.

5. Nuwaha F, Musinguzi G. Use of alternative medicine for hypertension in Buikwe and Mukono districts of Uganda: a cross sectional study. BMC Complement Altern Med. 2013;13:301. Published 2013 Nov 4. https://doi. org/10.1186/1472-6882-13-301.

6. World Health Organization. WHO Traditional Medicine Strategy 2002-2005. 2002. www.who.int/medicines/publications/traditionalpolicy/en/. Accessed June 1, 2019.

7. Khalaf AJ, Whitford DL. The use of complementary and alternative medicine by patients with diabetes mellitus in Bahrain: a cross-sectional study. BMC Complement Altern Med. 2010;10:35. Published 2010 Jul 14. https://doi.org/ 10.1186/1472-6882-10-35.

8. Caribbean Health Research Council and Pan American Health Organization. Managing Hypertension in Primary Care in the Caribbean. 2007. http:// carpha.org/Portals/0/docs/Clinical\%20Guidelines/Hypertension\%2 OGuidelines.pdf. Accessed June 1, 2019.

9. Bidulescu A, Francis DK, Ferguson TS, et al. Disparities in hypertension among black Caribbean populations: a scoping review by the U.S. Caribbean Alliance for Health Disparities Research Group (USCAHDR). Int J Equity Health. 2015:14:125. Published 2015 Nov 5. https://doi.org/10.1186/ s12939-015-0229-0.

10. Ragoobirsingh D, McGrowder D, Morrison EY, Johnson P, Lewis-Fuller E, Fray J. The Jamaican hypertension prevalence study. J Natl Med Assoc. 2002; 94(7):561-5.

11. Jamaica Observer. Diabetes, obesity, hypertension 'on the rise' in the Caribbean. http://www.jamaicaobserver.com/news/Diabetes\%2D\%2 Dobesity\%2D\%2Dhypertension\%2D\%2Don-the-rise\%2D\%2Din-theCaribbean. May 18, 2012. Accessed June 1, 2019

12. International Diabetes Federation. IDF North America and Caribbean members: Jamaica. https://www.idf.org/our-network/regions-members/ north-america-and-caribbean/members/65-jamaica.html. Accessed June 1 , 2019

13. Ferguson TS, Tulloch-Reid MK, Wilks RJ. The epidemiology of diabetes mellitus in Jamaica and the Caribbean: a historical review. West Indian Med J. 2010;59(3):259-64.

14. Picking D, Younger N, Mitchell S, Delgoda R. The prevalence of herbal medicine home use and concomitant use with pharmaceutical medicines in Jamaica. J Ethnopharmacol. 2011;137(1):305-11. https://doi.org/10.1016/j. jep.2011.05.025 Epub 2011 May 27.

15. Connell $P$, McKevitt C, Wolfe C. Strategies to manage hypertension: a qualitative study with black Caribbean patients. Br J Gen Pract. 2005;55(514): 357-61.

16. Mahabir D, Gulliford MC. Use of medicinal plants for diabetes in Trinidad and Tobago. Rev Panam Salud Publica. 1997:1(3):174-9.

17. Mitchell SA, Ahmad MH. A review of medicinal plant research at the University of the West Indies, Jamaica, 1948-2001. West Indian Med J. 2006; 55(4):243-69.

18. Delgoda R, Younger N, Barrett C, Braithwaite J, Davis D. The prevalence of herbs use in conjunction with conventional medicines in Jamaica. 
Complement Ther Med. 2010;18(1):13-20. https://doi.org/10.1016/j.ctim. 2010.01.002 Epub 2010 Feb 7.

19. Bourne PA, McDaniel S, Williams MS, Francis C, Kerr-Campbell MD, Beckford OW. The changing faces of diabetes, hypertension and arthritis in a Caribbean population. N Am J Med Sci. 2010;2(5):221-9. https://doi.org/10. 4297/najms.2010.221.

20. Desai P. Alternative medicine: old ideas with new interests? West Indian Med J. 1998:47(Suppl 4):34-6.

21. Lobban M. JAMAICA-HEALTH: A Return to Traditional Medicine. Development \& Aid, Headlines, Health, Latin America \& the Caribbean; Inter Press Service News Agency. 1996. Accessed May 27, 2020. http://www. ipsnews.net/1996/09/jamaica-health-a-return-to-traditional-medicine/.

22. Shabani E, Sayemiri K, Mohammadpour M. The effect of garlic on lipid profile and glucose parameters in diabetic patients: a systematic review and meta-analysis. Prim Care Diabetes. 2019;13(1):28-42. https://doi.org/10.1016/ j.pcd.2018.07.007.

23. Wang J, Zhang X, Lan H, Wang W. Effect of garlic supplement in the management of type 2 diabetes mellitus (T2DM): a meta-analysis of randomized controlled trials. Food Nutr Res. 2017;61(1):1377571. Published 2017 Sep 27. https://doi.org/10.1080/16546628.2017.1377571.

24. World Health Organization. Essential medicines and health products "Beijing declaration". 2008. www.who.int/medicines/areas/traditional/congress/ beijing_declaration/en/. Accessed June 1, 2019.

\section{Publisher's Note}

Springer Nature remains neutral with regard to jurisdictional claims in published maps and institutional affiliations.

Ready to submit your research? Choose BMC and benefit from:

- fast, convenient online submission

- thorough peer review by experienced researchers in your field

- rapid publication on acceptance

- support for research data, including large and complex data types

- gold Open Access which fosters wider collaboration and increased citations

- maximum visibility for your research: over $100 \mathrm{M}$ website views per year

At $\mathrm{BMC}$, research is always in progress.

Learn more biomedcentral.com/submissions 